\title{
Supplementation with vitamin A reduces watery diarrhoea and respiratory infections in Mexican children
}

\author{
Kurt Z. Long ${ }^{1}$, Jorge L. Rosado ${ }^{2}$, Herbert L. DuPont ${ }^{3}$, Ellen Hertzmark ${ }^{4}$ and Jose Ignacio Santos ${ }^{5}$ \\ ${ }^{1}$ Department of Nutrition, Harvard School of Public Health, 1663 Tremont Street, Boston, MA 02115, USA \\ ${ }^{2}$ School of Natural Sciences, Universidad Autónoma de Querétaro, Querétaro, 76160 México \\ ${ }^{3}$ Department of Clinical Medicine, University of Texas Medical School, Houston, TX 77083, USA \\ ${ }^{4}$ Department of Epidemiology, Harvard School of Public Health, Boston, MA 02115, USA \\ ${ }^{5}$ Hospital Infantil de Mexico 'Federico Gomez', Secretary of Health, Mexico City, 01900 Mexico
}

(Received 4 January 2006 - Revised 17 August 2006 - Accepted 20 August 2006)

\begin{abstract}
Previous clinical vitamin A trials have found no consistent effect on diarrhoeal disease and respiratory tract infection. These inconsistent results may be due to the distinct effects vitamin A supplementation has among children stratified by factors related to socio-economic status, nutritional status and season. We evaluated the effect of supplementation on the overall incidence of diarrhoeal disease and respiratory tract infections and on the incidence among children stratified by these factors. A total of 188 children, aged 6-15 months, from periurban, marginalized communities of Mexico City were assigned to receive vitamin A ( $<12$ months of age, 20000 IU retinol; $\geq 12$ months, 45000 IU retinol) or a placebo every 2 months, and were followed for up to 15 months. Project personnel visited households twice a week to determine the onset and duration of diarrhoeal disease and respiratory tract infections. Vitamin A supplementation had no significant effect on risk of overall diarrhoeal disease but reduced mild watery diarrhoea (incidence rate ratio (RR) 0.69; $95 \%$ CI $0.50,0.93$ ) and cough with fever (RR 0.69; $95 \%$ CI $0.48,0.98$ ). Vitamin A supplementation decreased diarrhoeal disease during the summer (RR 0.74; $95 \%$ CI 0.57, 0.94), among non-stunted children (RR 0.69; $95 \%$ CI $0.52,0.93$ ) and among children from households with better socio-economic measures. Heterogeneity in the response to vitamin A supplementation may reflect heterogeneity in the aetiology and epidemiology of diarrhoeal disease and respiratory tract infections and the impact that supplementation has on the immune response.
\end{abstract}

Vitamin A: Diarrhoea: Respiratory tract infections: Children: Mexico

Vitamin A supplementation has proven to be one of the most cost-effective interventions for reducing mortality and severity of infectious disease episodes among young children in developing countries (Hussey \& Klein, 1990; Beaton et al. 1992; Fawzi et al. 1993). Paradoxically, randomized, placebo-controlled trials carried out in different parts of the world have not found a consistent effect on the incidence of diarrhoeal disease or respiratory tract infections (Ghana VAST Study Team, 1993; Stansfield et al. 1993; Barreto et al. 1994; Ramakrishnan et al. 1995; Dibley et al. 1996; Grotto et al. 2003). This inconsistency is difficult to explain, since a reduction in disease incidence would be an obvious mechanism responsible for child mortality reductions. One possible explanation may be that vitamin A supplementation is reducing case fatalities. However, a number of recently published studies have reported that vitamin A reduces morbidity among malnourished children while simultaneously increasing morbidity among well-nourished children (Dibley et al. 1996; Sempertegui et al. 1999; Fawzi et al. 2000). These earlier results suggest that differences in childhood characteristics may be modifying the effect vitamin A supplementation has on morbidity. Any heterogeneity in effect introduced by such characteristics may be attenuated when the analysis is carried out at a more aggregate population level, and this could explain the failure to find an overall impact of vitamin A.

There may be extensive heterogeneity in diarrhoeal disease incidence within and between communities in developing countries due to differences in household access to potable water and sanitation facilities (Esrey, 1996). In Latin America the construction of water and sanitary facilities and the implementation of diarrhoeal disease prevention programmes have led to important reductions in diarrhoeal disease (Velazquez et al. 2004). These reductions have not occurred uniformly throughout the region due to the incomplete implementation of such systems and programmes. Older, more established communities found around the periphery of large metropolitan centres have access to water and sanitary facilities, but more recently founded communities have little or no access. These differences can determine the children's degree of exposure to specific enteric and respiratory pathogens, and so may modify the effect supplementation has on

Abbreviations: RR, incidence rate ratio; SES, socio-economic status; Th1, T helper type 1; Th2, T helper type 2.

* Corresponding author: Dr Kurt Z. Long, fax (617) 432-1335, email klong@ hsph.harvard.edu 
specific childhood health outcomes. Further studies are needed to address how the impact of vitamin A may differ between children stratified by household and environmental characteristics related to hygiene and pathogen exposure. This understanding may clarify what is responsible for inconsistencies found in previous studies which have largely focused on the aggregate effect of vitamin A. It could then allow the development of more cost-effective vitamin A supplementation strategies in regions where epidemiological transitions are occurring.

We have carried out a community-based, randomized, double-blind, placebo-controlled trial of the impact of vitamin A supplementation on diarrhoeal disease and respiratory tract infections among children from Mexico City, Mexico. In this paper we address the hypothesis that vitamin A supplementation reduces rates of diarrhoeal disease and respiratory tract infections and that household and environmental factors and season act as effect modifiers on this association.

\section{Subjects and methods}

\section{Study area subjects and recruitment}

The present study was carried out in peri-urban communities that are part of the municipality of La Magdalena Atlicpac located along the eastern perimeter of Mexico City. These communities are made up of households that have migrated at different times into the Valley of Mexico and, as a result, differ in their degree of access to piped water, sanitary facilities and overall development. Community health workers first carried out a census of all children less than 2 years of age living within these communities. Mothers of all eligible children between the ages of 6 and 15 months were invited to participate in the trial during household visits by project personnel. Restricting the study to children of this age range would allow us to evaluate the efficacy of supplementation during the period when the children's immune response is developing. Children were excluded from the study if they had diseases causing immunosuppression, or any congenital or acquired alteration of the digestive tract that could alter the absorption of micronutrients. Children who were taking vitamin supplements were also excluded from the study. Overall, 200 children were enrolled in the study after their parents had given informed consent for their participation.

\section{Study design}

The children, once enrolled, were randomly assigned to receive vitamin A or a placebo balanced in blocks of twenty. Children less than 12 months of age assigned to the vitamin A group were administered a solution containing $20000 \mathrm{IU}$ of retinol [3.3 IU $=1$ retinol activity equivalent $(\mu \mathrm{g})]$ at baseline and subsequently every 2 months until the end of the study while children older than 12 months received a solution containing $45000 \mathrm{IU}$ of retinol. This dosage would allow the evaluation of the impact of frequent low doses of vitamin $\mathrm{A}$ on rates of diarrhoeal disease and respiratory tract infections.

The randomization sequence was generated by project personnel based at the National Institute of Public Health. Personnel at the National Institute of Nutrition carried out the preparation of the supplements to assure that field personnel and the principal investigator were unaware of treatment regimen. Children in the vitamin A and placebo groups received a $5 \mathrm{ml}$ solution, from identical opaque plastic droplet bottles numbered consecutively, administered by the field team. Testing had been carried out at the National Institute of Nutrition to assure that the placebo and vitamin A water miscible solution were similar in taste, viscosity and colour.

At the first household visit, mothers were interviewed to determine the child's morbidity experience in the previous 2 weeks. Information was also collected regarding the number of household members, their ages, education levels and income, household construction materials, the source and quality of household water, the type of household sanitation facilities and number of possessions that are electrical domestic appliances. Finally, during this initial visit the mother or child caretaker was asked to describe the feeding and weaning patterns of the child. A previously validated questionnaire was used in the collection of these data by project personnel who had received training in its application.

Children were then followed prospectively for up to 15 months, with field personnel visiting households twice a week. Mothers were interviewed during these visits to determine if the child had had the following symptoms: diarrhoea, the presence of blood and mucus in stools, cough, difficulty breathing and fever, and they were asked to report on the number and consistency of evacuations by the child. Project supervisors accompanied approximately $5 \%$ of all household visits to assure quality of data collection. Children were referred to the study physician for diagnosis and treatment when the fieldworker or caregiver was concerned about the child's health status.

Trained personnel obtained weight and height measurements from each child at the first household visit and once a month thereafter to evaluate the nutritional status of each child using calibrated methods and standardized techniques. Children were weighed using a calibrated Salter scale (Salter Weigh-Tronix Ltd, Monterrey, Mexico) while wearing light clothing and their supine length was measured using a locally constructed rigid measuring board. Training exercises at the beginning of the study and at repeated intervals thereafter were used to standardize these personnel.

The mother's reporting of symptoms in the child was used to define diarrhoeal disease episodes. A period of three or more, symptom-free days was used in this analysis to define the end of an episode. Acute diarrhoea was defined as an episode that lasted between 1 and $14 \mathrm{~d}$ while persistent diarrhoea was defined as lasting more than $14 \mathrm{~d}$. Acute diarrhoea was classified as dysentery if blood or pus was present in the stool or watery diarrhoea if no blood or pus was present. All episodes of watery diarrhoea or dysentery were classified as mild or moderate if the child passed $<5$ movements on the worst day or passed $\geq 5$ movements but the episode lasted $\leq 3 \mathrm{~d}$; an episode was considered severe if the child had $\geq 5$ movements on the worst day and the episode lasted $>3 \mathrm{~d}$ (Fawzi et al. 2000). These subgroups of diarrhoea were mutually exclusive. Respiratory tract infection outcomes were classified as cough alone, cough and fever, or cough and rapid respiratory rate as reported by the mother. A new episode was defined if there was an interval of $14 \mathrm{~d}$ or more free of symptoms. 


\section{Sample size and power}

Sample sizes were calculated based on the assumption that the study population has a diarrhoeal disease rate of three episodes per child per year and that the vitamin A supplement would reduce this rate by approximately $20 \%$. This effect approximated the reduction in diarrhoea incidence reported by Barreto et al. (1994) in their vitamin A trial in Brazil. It was calculated that a sample size of 100 per group was required to detect a $20 \%$ reduction between the control and treatment group with a power of $80 \%$ and $95 \%$ significance level and an expected loss to follow-up of $20 \%$. This calculation allowed for repeated measurements of the outcome and a correlation between measurements at different time-points of $0 \cdot 7$ (Frison \& Pocock, 1992).

\section{Statistical analysis}

Data were entered in Visual Fox Pro 6.0 (Microsoft), verified, and checked for range and consistency. Anthropometric indicators were calculated by using sex- and age-specific standards developed by the US Centers for Disease Control and Prevention (Ogden et al. 2002). Children with height-for-age $Z$-scores below -2 were considered stunted, those with weight-for-age $Z$-scores below -2 were classified as underweight children. Children with $Z$-scores at or above -2 in both measurements were classified as non-stunted or normal weight-for-age.

The end-points for the study were the incidence of diarrhoeal episodes and respiratory tract infections during the follow-up of each child. The rate ratio (RR) and $95 \% \mathrm{CI}$ for the overall incidence of diarrhoeal disease and respiratory tract infections were estimated by fitting Poisson regression models to counts of diarrhoea and respiratory infections in the treatment and placebo groups (Gardner et al. 1995). These primary analyses were 'intent to treat'. Separate models were also adjusted to counts of episodes stratified by child and household characteristics as well as season in an effort to disaggregate the overall effect of vitamin A. The variables of special interest in this analysis were those that may be indirect measures of pathogen prevalence and transmission such as water source (piped water, no piped water), availability of indoor toilets (indoor toilet, no indoor toilet), presence of refrigerator (refrigerator, no refrigerator), the number of household goods as a measure of socio-economic status (SES; $<3, \geq 3$ ), the season in which the episode occurred (winter and summer) and the child's age and nutritional status (stunted, non-stunted). The stratification by season was carried out due to the prevalence of distinct diarrhoeal disease and respiratory tract infection pathogens in Mexico during the winter (November to March) and summer seasons (April to October) (Golubjatnikov et al. 1975; Cravioto et al. 1990). All analyses included child's age and breastfeeding status (breastfed, not breastfed). Statistical significance was set at a probability level of $<0.05$ and at $<0.1$ for interactions. Data were analysed using the PROC GENMOD procedure in the Statistical Analysis System software (SAS version 8.2; SAS Institute, Cary, NC, USA). The study protocol was approved by the human subjects committees of the National Institute of Public Health of Mexico and Harvard School of Public Health.

\section{Results}

In all, 200 children were recruited for the study following the consent of their mothers. Five children were excluded from the study due to receiving a vitamin A supplement prior to enrollment or due to their extreme low weightfor-age $Z$-scores and seven children were lost to followup. The remaining 188 children were followed for up to 15 months, ninety-three children in the vitamin A group and ninety-five children in the placebo group (Fig. 1). The distribution of sociodemographic characteristics of study children and households was similar between children who received vitamin $\mathrm{A}$ and those who were given the placebo (Table 1). Approximately $47-50 \%$ of households had no access to piped water while approximately 64-70\% had no indoor toilets; $34-40 \%$ of children were stunted. The mean duration of follow-up for children in the two treatment groups was not significantly different (vitamin A group, 11.5 (SE 5.5) months; placebo group, 11.9 (SE 5.6) months; $P=0 \cdot 56$ ). Approximately 1035 of the planned 1120 doses of vitamin A or placebo were given by the project personnel and consumed by the study children for a compliance rate of $92 \%$.

There were significantly fewer episodes of mild watery diarrhoea among children in the vitamin A group compared to children in the placebo group (RR 0.69; $95 \%$ CI 0.50 , 0.93 ) (Table 2). There was no significant difference in the incidence and duration of overall diarrhoea, severe diarrhoea or dysentery among children receiving vitamin A and children in the placebo group (Table 2). There were only two episodes of persistent diarrhoea, both occurring in the placebo group. Children in the vitamin A group had significantly fewer episodes of cough with fever compared to children in the placebo group (RR 0.69; $95 \%$ CI 0.48, 0.98; Table 3). There were no significant differences between the vitamin A and placebo groups in the incidence or duration of the other types of respiratory infections.

Vitamin A was found to have significant effects on diarrhoea among some subsets of children. In this analysis diarrhoeal rates in the placebo group were higher among children with better anthropometric measures, who were from households with better SES measures, and during the summer months compared to rates among children with worse anthropometric measures, from household with poorer SES measures and during the winter season (Table 4). Vitamin A was associated with a reduction in diarrhoea among children during the summer season compared to the placebo group (RR 0.74; $95 \%$ CI 0.57, 0.94). This effect was significantly different from that found among children during the winter months when vitamin A supplementation had no effect on diarrhoea incidence $(P$ value for interaction: $<0.01)$. Significant interactions between vitamin $\mathrm{A}$ and refrigerator availability, and vitamin $\mathrm{A}$ and greater household possessions were found (Table 4; $P$ value for interaction: 0.03 and 0.02, respectively). Diarrhoea was lower among vitamin A-supplemented children from households that had refrigerators (RR 0.53; $95 \%$ CI 0.36, 0.77) and that had two or more household possessions (RR 0.57 ; $95 \%$ CI $0 \cdot 38,0 \cdot 86)$. There was no difference in respiratory infections between vitamin A-supplemented children and children in the placebo group in the stratified analysis. 


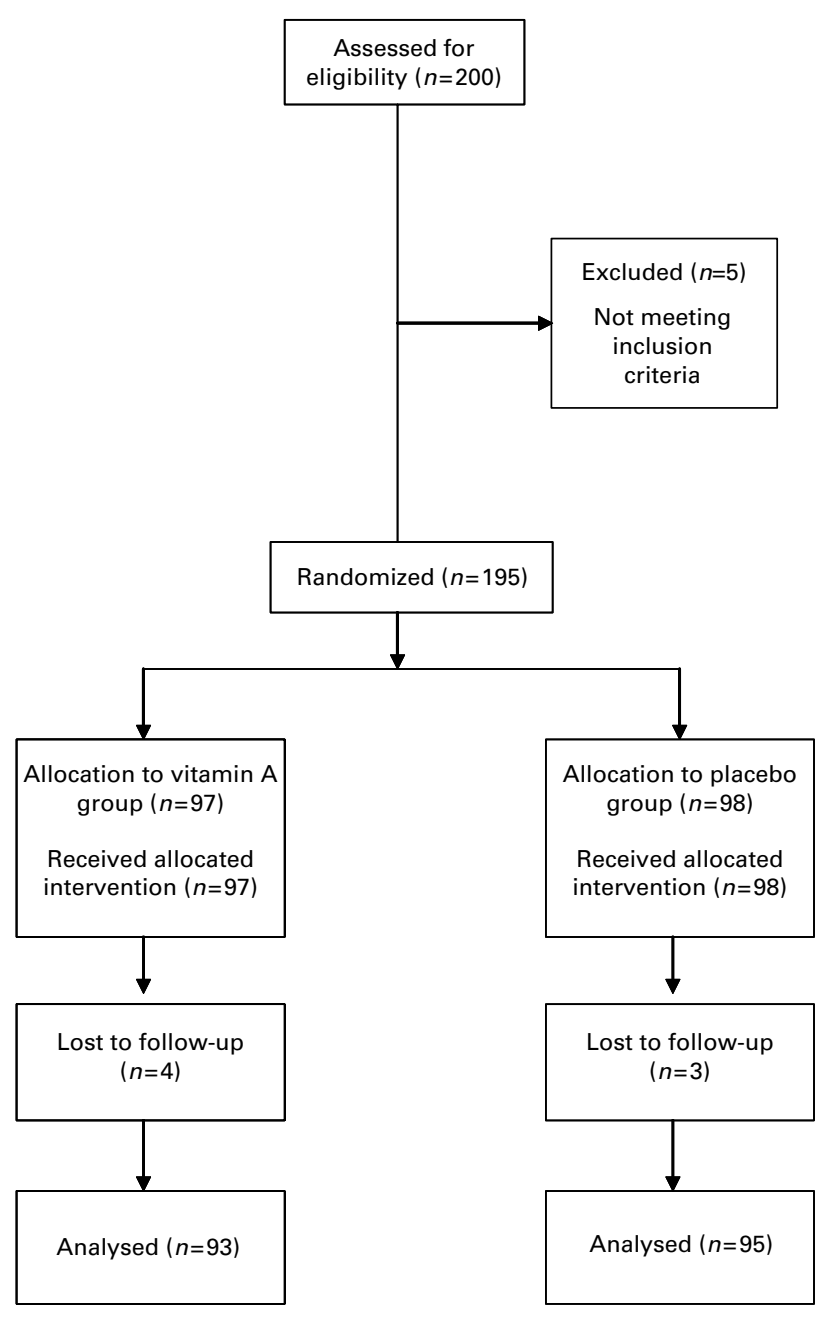

Fig. 1. Trial profile.

\section{Discussion}

We have found in a randomized clinical trial carried out in a peri-urban area of Mexico City that vitamin A supplementation was associated with reductions in the rates of mild watery diarrhoea and cough with fever but had no effect on the overall rate of diarrhoea. A reduction in diarrhoeal disease was found among vitamin A-supplemented children from households with better SES measures and during the summer months. No differences in the effect of vitamin A on respiratory infections were found in the stratified groups. The present findings suggest that vitamin A supplementation does not have an overall effect on all morbidity outcomes but does have an effect on specific outcomes and among children stratified by personal and household characteristics and by season.

Previously published studies have shown that the effect of vitamin A on diarrhoeal disease and respiratory tract infections in stratified analyses can be quite different from effects found at an aggregate level. Trials which have reported no overall effect on diarrhoea have simultaneously reported both reductions and increases in diarrhoea among children stratified by age, nutritional status and feeding mode (Ramakrishnan et al. 1995; Dibley et al. 1996; Fawzi et al.
Table 1. Baseline characterisitics of study children and households

\begin{tabular}{|c|c|c|c|}
\hline \multirow[b]{2}{*}{ Characteristics } & \multicolumn{2}{|c|}{$\begin{array}{l}\text { Percentage with } \\
\text { characteristics }\end{array}$} & \multirow[b]{2}{*}{$P$ value* } \\
\hline & $\begin{array}{l}\text { Vitamin A } \\
(n 93)\end{array}$ & $\begin{array}{l}\text { Placebo } \\
(\text { ( } 95)\end{array}$ & \\
\hline \multicolumn{4}{|l|}{ Child age } \\
\hline $6-12$ months & $82 \cdot 4$ & $81 \cdot 3$ & \\
\hline $12-18$ months & $18 \cdot 1$ & 17.5 & 0.64 \\
\hline Boys & $49 \cdot 2$ & $50 \cdot 2$ & 0.43 \\
\hline \multicolumn{4}{|l|}{ Mother's education } \\
\hline Less than 6 years & $43 \cdot 4$ & $35 \cdot 1$ & \\
\hline Completed elementary & 35.5 & 41.9 & \\
\hline Completed secondary & $11 \cdot 8$ & $12 \cdot 1$ & \\
\hline Greater than secondary & $9 \cdot 2$ & $10 \cdot 8$ & 0.76 \\
\hline \multicolumn{4}{|l|}{ Water source } \\
\hline Indoor tap & $15 \cdot 5$ & $15 \cdot 1$ & \\
\hline Outdoor tap & $34 \cdot 6$ & $37 \cdot 3$ & \\
\hline No access to piped water & 49.8 & 47.5 & 0.85 \\
\hline \multicolumn{4}{|l|}{ Bathroom } \\
\hline Inside house & $28 \cdot 7$ & 34.5 & \\
\hline Outside house & $69 \cdot 8$ & $63 \cdot 8$ & \\
\hline No bathroom & 1.3 & $2 \cdot 4$ & 0.63 \\
\hline \multicolumn{4}{|c|}{ Number of household appliances } \\
\hline None & $6 \cdot 9$ & $7 \cdot 3$ & \\
\hline $1-2$ & $67 \cdot 1$ & $67 \cdot 0$ & \\
\hline $3-4$ & $24 \cdot 6$ & $20 \cdot 7$ & \\
\hline $5-6$ & 1.4 & 4.9 & 0.63 \\
\hline \multicolumn{4}{|l|}{ Refrigerator in house } \\
\hline No & $72 \cdot 6$ & $69 \cdot 1$ & \\
\hline Yes & $27 \cdot 4$ & $30 \cdot 9$ & 0.64 \\
\hline \multicolumn{4}{|l|}{ Height-for-age Z-score } \\
\hline$<-2$ & $40 \cdot 0$ & $33 \cdot 8$ & \\
\hline-2 to -1 & $32 \cdot 7$ & $40 \cdot 0$ & \\
\hline$>-1$ & $27 \cdot 2$ & $26 \cdot 1$ & 0.69 \\
\hline \multicolumn{4}{|l|}{ Weight-for-height $Z$-score } \\
\hline$<-2$ & $10 \cdot 9$ & $6 \cdot 0$ & \\
\hline-2 to -1 & $25 \cdot 4$ & $28 \cdot 3$ & \\
\hline$>-1$ & $63 \cdot 6$ & $65 \cdot 6$ & 0.14 \\
\hline
\end{tabular}

2000). Similarly, trials which have reported no consistent effect or even a negative effect of vitamin A on respiratory tract infections have reported quite different effects between children who were stratified by nutritional status, age and HIV status (Dibley et al. 1996; Sempertegui et al. 1999; Fawzi et al. 2000). These reported differences suggest that vitamin A supplementation may be producing effects through mechanisms that are not clearly understood at present.

Such complexity may be partly due to the impact vitamin A has on the host's immune response against specific pathogens. Vitamin A supplementation up-regulates the T helper type 2 (Th2) lymphocyte response which is protective against such pathogens as Ascaris lumbricoides (Cooper et al. 2000) and down-regulates the $\mathrm{T}$ helper type 1 (Th1) lymphocyte response protective against intracellular infections such as $\mathrm{Sal}$ monella spp. (Mizuno et al. 2003). Vitamin A deficiency, in contrast, down-regulates the Th2 response and up-regulates the Th1 response (Wiedermann et al. 1993; Cantorna et al. 1994, 1995; Long et al. 2006a). These regulatory effects of vitamin $\mathrm{A}$ on the immune response suggests that effectiveness of supplementation in modifying pathogen-specific clinical outcomes may depend on the role of the Th1-Th2 responses in these outcomes. 
Table 2. Incidence rate of diarrhoea among study children administered vitamin A or placebo

\begin{tabular}{|c|c|c|c|c|c|c|c|c|}
\hline & \multicolumn{3}{|c|}{ Vitamin A group } & \multicolumn{3}{|c|}{ Placebo group } & \multirow[b]{2}{*}{$\mathrm{RR}^{*}$} & \multirow[b]{2}{*}{$95 \% \mathrm{Cl}$} \\
\hline & No. of episodes & Child-years at risk & Incidence rate & No. of episodes & Child-years at risk & Incidence rate & & \\
\hline Diarrhoea (all types) & 214 & $58 \cdot 7$ & 3.64 & 250 & 63.1 & 3.96 & 0.79 & $0.60,1.02$ \\
\hline Mild watery diarrhoea & 154 & 58.2 & $2 \cdot 64$ & 161 & $62 \cdot 4$ & $2 \cdot 58$ & 0.68 & $0.50,0.93$ \\
\hline Severe watery diarrhoea & 53 & 57.6 & 0.91 & 76 & 61.9 & 1.22 & 0.90 & $0.51,1.59$ \\
\hline Dysentery & 9 & $58 \cdot 8$ & 0.15 & 19 & $62 \cdot 3$ & 0.30 & 0.60 & $0.14,2.50$ \\
\hline
\end{tabular}

*Incidence relative rates (RR) calculated using Poisson regression models; child's age, breastfeeding status, season, nutritional status and household socio-economic status characteristics were included in the models.

Table 3. Incidence rate of respiratory symptoms among study children administered vitamin A or placebo

\begin{tabular}{|c|c|c|c|c|c|c|c|c|}
\hline & \multicolumn{3}{|c|}{ Vitamin A group } & \multicolumn{3}{|c|}{ Placebo group } & \multirow[b]{2}{*}{$\mathrm{RR}^{*}$} & \multirow[b]{2}{*}{$95 \% \mathrm{Cl}$} \\
\hline & No. of episodes & Child-years at risk & Incidence rate & No. of episodes & Child-years at risk & Incidence rate & & \\
\hline Cough & 179 & $56 \cdot 5$ & $3 \cdot 16$ & 206 & $60 \cdot 1$ & 3.42 & 0.73 & $0.68,1.09$ \\
\hline Cough with difficulty breathing & 24 & $53 \cdot 1$ & 0.45 & 17 & $56 \cdot 5$ & 0.30 & 1.03 & $0.49,2.17$ \\
\hline Cough with fever & 84 & $54 \cdot 3$ & 1.54 & 113 & 58.5 & 1.93 & 0.69 & $0.48,0.98$ \\
\hline
\end{tabular}

${ }^{*}$ Incidence relative rates (RR) calculated using Poisson regression models; child's age and breastfeeding status were included in the model.

Table 4. Impact of vitamin A on the incidence of diarrhoea among children stratified by personal and household characteristics

\begin{tabular}{|c|c|c|c|c|c|c|c|c|c|c|c|}
\hline \multirow[b]{2}{*}{ Modifier } & \multirow[b]{2}{*}{ Level } & \multicolumn{3}{|c|}{ Vitamin A } & \multicolumn{3}{|c|}{ Placebo } & \multirow[b]{2}{*}{$\mathrm{RR}^{*}$} & \multirow[b]{2}{*}{$95 \% \mathrm{Cl}$} & \multirow[b]{2}{*}{$P$ value } & \multirow[b]{2}{*}{$P$ for interaction } \\
\hline & & Episodes & Child-years & Incidence rate & Episodes & Child-years & Incidence rate & & & & \\
\hline \multirow[t]{2}{*}{ Season } & Winter & 61 & $20 \cdot 7$ & 2.94 & 55 & $23 \cdot 7$ & $2 \cdot 31$ & 1.31 & $0.91,1.90$ & 0.14 & $<0.01$ \\
\hline & Summer & 153 & 37.9 & 4.03 & 195 & $39 \cdot 3$ & 4.95 & 0.74 & $0.57,0.94$ & 0.01 & \\
\hline \multirow[t]{2}{*}{ No. of possessions } & $\leq 2$ & 152 & 39.5 & 3.84 & 167 & 42.9 & 3.89 & 0.91 & $0.71,1.17$ & 0.47 & 0.01 \\
\hline & $>2$ & 30 & 12.5 & 2.39 & 68 & $15 \cdot 4$ & 4.40 & 0.57 & $0.38,0.86$ & $<0.01$ & \\
\hline \multirow[t]{2}{*}{ Refrigerator } & No & 147 & $37 \cdot 3$ & 3.93 & 138 & $37 \cdot 6$ & 3.66 & 0.8 & $0.68,1.13$ & 0.33 & 0.03 \\
\hline & Yes & 35 & 14.7 & $2 \cdot 38$ & 93 & $20 \cdot 0$ & 4.65 & 0.53 & $0.36,0.77$ & $<0.01$ & \\
\hline Height-for-age & $<-2$ & 64 & 14.8 & 4.32 & 44 & $15 \cdot 0$ & 2.92 & 1.08 & $0.68,1.73$ & 0.72 & 0.08 \\
\hline$Z$-score & $\geq-2$ & 80 & 24.7 & $3 \cdot 22$ & 147 & $33 \cdot 1$ & 4.42 & 0.69 & $0.52,0.93$ & 0.01 & \\
\hline
\end{tabular}

${ }^{*}$ Incidence relative rates (RR) calculated using Poisson regression models; child's age and breastfeeding status were included in the model. 
The regulation of the immune response by vitamin A may underlie the effect supplementation has on diarrhoeal disease and respiratory tract infections in different community settings. The lack of a clear, overall effect of supplementation on diarrhoeal disease may be due to the treatment of diarrhoeal disease as aetiologically a single disease. There is, in fact, a very extensive group of pathogens that can cause diarrhoeal disease, each of which can have quite distinct transmission routes and means of inducing pathogenesis (Farmer \& Kelly, 1991; DuPont \& Mathewson, 1998; Long et al. 1999). The grouping together of all diarrhoeas regardless of cause may be obscuring pathogenspecific effects of vitamin A supplementation and so may be biasing results towards the null (Long et al. 2006c). In contrast, the significant reduction of mild watery diarrhoea may reflect the effect of vitamin A supplementation on a more restricted range of pathogens. We have found that vitamin A supplementation is associated with reductions in watery diarrhoea associated with norovirus infections (Long et al. 2006b). Similarly, the clear effect of supplementation on the overall incidence of cough with fever may reflect the impact of supplementation on the immune response to a much smaller number of pathogens that cause respiratory tract infections (Wilhelmi \& A, 2003).

The effects of supplementation on diarrhoea seen in children stratified by season and household characteristics could reflect the immuno-regulatory effects of vitamin A between children exposed to distinct groups of pathogens. There is a strong seasonal prevalence of different types of diarrhoeal disease pathogens in Mexico City, with rotavirus being the most prevalent diarrhoeal pathogen in the winter months, and diarrhoeal Escherichia coli and norovirus being more prevalent in the summer months (Calva et al. 1988; Velazquez et al. 1996; Long et al. 2006b). The up-regulation of a Th2 response by vitamin A may have contributed to the decrease in diarrhoea in the summer. This response is protective against such pathogens as enterotoxigenic $E$. coli and norovirus which are more prevalent during this period (Long et al. 1994, 2006b). In contrast, a developed Th1 response may be more protective against rotavirus (VanCott et al. 2000). The down-regulation of this response among vitamin A-supplemented children could have led to a non-significant, greater prevalence of rotavirus among these children in the winter season.

The impact of supplementation on children when stratified by household characteristics may again reflect the children's exposure to different types of diarrhoeal pathogens. In this case the number of household possessions and the presence or absence of refrigerator may serve as markers for the transmission of such pathogens (Bandres et al. 1988; Levine et al. 1993). However, the consistently beneficial effect of supplementation on diarrhoea among children from households with better SES measures is paradoxical. Norovirus, an enteral virus increasingly recognized as an important cause of paediatric diarrhoea in developing countries, was the most prevalent pathogen isolated in the summer (Long et al. 2006 b). The incidence of this pathogen and the reductions associated with supplementation were greatest among children from households that had refrigerators and that had better SES measures. The paradoxical effect of supplementation in the stratified analysis may reflect the relative importance of diarrhoeas due to this pathogen compared to other enteropathogens (Long et al. $2006 c$ ).
The lack of differential effects of supplementation on cough with fever in the stratified analysis may reflect the epidemiology of respiratory tract infections. The transmission of respiratory tract pathogens does not involve any environmental component since transmission is largely through direct person-to-person contact (Berman, 1991). As a result, the exposure of children to these pathogens could be more evenly distributed through a community regardless of household differences in SES characteristics such as sanitation or water availability.

One limitation of the present study is that we have no indicators of the children's pre-randomization vitamin A status. Differences in the initial status of study children could possibly determine the effectiveness of supplementation with deficient children benefiting more and non-deficient children benefiting less. No blood samples were taken from children in the present study, so it was not possible to address their vitamin A status. A probabilistic national survey carried out in Mexico has shown that overt vitamin A deficiency $(<100 \mu \mathrm{g} / \mathrm{l})$ and sub-clinical deficiency $(100-200 \mu \mathrm{g} / \mathrm{l})$ among children living in Mexico City is minimal (Villalpando et al. 2003). A second limitation is that we have not presented any pathogen-specific effects associated with vitamin A supplementation.

We have suggested that the distinct effects of vitamin A supplementation on specific outcomes may reflect its impact on the host's pathogen-specific immune response. The present findings suggest there is a greater heterogeneity of effects in the children's response to supplementation for diarrhoeal disease episodes than for respiratory tract infections. If further work shows that vitamin $\mathrm{A}$ is protective against a specific group of pathogen infections then it would be imperative to design vitamin A supplementation programmes that target groups of children that would benefit most. The timing of supplementation based on the seasonal prevalence of such pathogens is one obvious strategy which could potentially enhance the effectiveness of supplementation programmes.

\section{Acknowledgements}

We thank members of the Clinical Microbiological Laboratory, Hospital La Perla, Secretary of Health, Cda Netzahuaycoytl, Mexico and members of the Center for Childhood and Adolescent Health, Secretary of Health, Mexico City, Mexico for their assistance. This paper was presented in part at the Annual Meeting of Experimental Biology, Washington, DC, USA, 17-21 April 2004 (abstract 37.7). This study was supported by grants from the National Council of Science and Technology of Mexico and National Institutes of Health grant no. K01 DK06142-02.

\section{References}

Bandres JC, Mathewson JJ \& DuPont HL (1988) Heat susceptibility of bacterial enteropathogens. Implications for the prevention of travelers' diarrhea. Arch Intern Med 148, 2261-2263.

Barreto ML, Santos LM, Assis AM, Araujo MP, Farenzena GG, Santos PA \& Fiaccone RL (1994) Effect of vitamin A supplementation on diarrhoea and acute low-respiratory-tract infections in young children in Brazil. Lancet 344, 228-231. 
Beaton GH, Martorell R, L'Abbe KA, Edmonston B, McGabe G, Ross AC \& Harvey B (1992) Effectiveness of Vitamin A Supplementation in the Control of Young Child Mortality in Developing Countries. Final Report to CIDA. Toronto: University of Toronto.

Berman S (1991) Epidemiology of acute respiratory infections in children of developing countries. Rev Infect Dis 6, Suppl., S454-S462.

Calva JJ, Ruiz-Palacios GM, Lopez-Vidal AB, Ramos A \& Bojalil R (1988) Cohort study of intestinal infection with campylobacter in Mexican children. Lancet 1, 503-506.

Cantorna MT, Nashold E \& Hayes C (1995) Vitamin A deficiency results in a priming environment conducive for Th1 cell development. J Immunol 25, 1673-1679.

Cantorna MT, Nashold FE \& Hayes C (1994) In vitamin A deficiency multiple mechanisms establish a regulatory $\mathrm{T}$ helper cell imbalance with excess Th1 and insufficient Th2 function. J Immunol 152, $1515-1522$.

Cooper PJ, Chico ME, Sandoval C, Espinel I, Guevara A, Kennedy MW, Urban JF Jr, Griffin GE \& Nutman TB (2000) Human infection with Ascaris lumbricoides is associated with a polarized cytokine response. J Infect Dis 182, 1207-1213.

Cravioto A, Reyes RE, Trujillo F, Uribe F, Navarro A, De La Roca JM, Hernandez JM, Perez G \& Vazquez V (1990) Risk of diarrhea during the first year of life associated with initial and subsequent colonization by specific enteropathogens. Am J Epidemiol 131, 886-904.

Dibley MJ, Sadjimin T, Kjolhede CL \& Moulton LH (1996) Vitamin A supplementation fails to reduce incidence of acute respiratory illness and diarrhea in preschool-age Indonesian children. $J$ Nutr 126, 434-442.

DuPont HL \& Mathewson JJ (1998) Escherichia coli diarrhea. In Bacterial Infections of Humans [AS Evans and PS Brachman, editors]. New York: Plenum Medical Book Company.

Esrey SA (1996) Water, waste, and well-being: a multicountry study. Am J Epidemiol 143, 608-623.

Farmer JJ \& Kelly MT (1991) Enterobacteriacea. In Manual of Clinical Microbiology, 5th ed., [A Balows, WJ Hausler and KL Hermann, editors]. New York: ASM.

Fawzi WW, Chalmers TC, Herrera MG \& Mosteller F (1993) Vitamin A supplementation and child mortality. A meta-analysis. JAMA 269, 898-903.

Fawzi WW, Mbise R, Spiegelman D, Fataki M, Hertzmark E \& Ndossi G (2000) Vitamin A supplements and diarrheal and respiratory tract infections among children in Dar es Salaam, Tanzania. J Pediatr 137, 660-667.

Frison L \& Pocock S (1992) Repeated measures in clinical trials: analysis using mean summary statistics and its implications for design. Stat Med 11, 1685-1704.

Gardner W, Mulvey EP \& Shaw E (1995) Regression analysis of counts and rates: Poisson, Overdispersed Poisson, and Negative Binomial. Psychol Bull 188, 392-404.

Ghana VAST Study Team (1993) Vitamin A supplementation in northern Ghana: effects on clinic attendances, hospital admissions, and child mortality. Lancet 342, 7-12.

Golubjatnikov R, Allen VD, Olmos-Blancarte MP \& Inhorn SL (1975) Serological profile of children in a Mexican highland community: prevalence of complement-fixing antibodies to Mycoplasm Pneumoniae, Respiratory Syncitial virus and Parainfluenza viruses. Am J Epidemiol 101, 458-464.

Grotto I, Mimouni M, Gdalevich M \& Mimouni D (2003) Vitamin A supplementation and childhood morbidity from diarrhea and respiratory infections: a meta-analysis. J Pediatr 142, 297-304.

Hussey GD \& Klein M (1990) A randomized controlled trial of vitamin A in children with severe measles. $N$ Engl J Med 323, 160-164.

Levine MM, Ferreccio C, Prado V, Cayazzo M, Abrego P, Martinez J, Maggi L, Baldini MM, Martin W \& Maneval D (1993) Epidemiological studies of Escherichia coli diarrheal infections in a low socioeconomic level peri-urban community in Santiago, Chile. Am J Epidemiol 138, 849-869.
Long K, Vasquez-Garibay E, Mathewson JJ, de la Cabada J \& DuPont H (1999) The impact of infant feeding patterns on infection and diarrheal disease due to enterotoxigenic Escherichia coli. Salud Publ Mex 41, 263-270.

Long KZ, Estrada T, Santos JI, Haas M, Rosado JL, Firestone M, Bhagwat J, Young C, DuPont HL, Hertzmark E \& Nanthakumar N (2006a) The impact of vitamin A supplementation on the intestinal immune response in Mexican children is modified by pathogen infections and diarrhea. J Nutr 136, 1365-1370.

Long KZ, Garcia C, Santos JI, Rosado JL, Hertzmark E, DuPont HL \& Ko G (2006b) Impact of vitamin A supplementation on Norovirus infections and diarrhea in Mexican children. In 2006 Experimental Biology Meeting Abstracts, vol. 20, abstract no. 399.6 FASEB, San Francisco.

Long KZ, Santos JI, Rosado JL, Lopez-Saucedo C, ThompsonBonillo R, Abonce M, DuPont HL, Hertzmark E \& EstradaGarcia T (2006c) Impact of Vitamin A on selected gastrointestinal pathogen infections and associated diarrheal episodes among children in Mexico City, Mexico. J Infect Dis 194, $1217-1225$.

Long KZ, Wood JW, Vasquez Gariby E, Weiss KM, Mathewson JJ, de la Cabada FJ, DuPont HL \& Wilson RA (1994) Proportional hazards analysis of diarrhea due to enterotoxigenic Escherichia coli and breast feeding in a cohort of urban Mexican children. Am J Epidemiol 139, 193-205.

Mizuno Y, Takada H, Nomura A, Jin CH, Hattori H, Ihara K, Aoki T, Eguchi K \& Hara T (2003) Th1 and Th1-inducing cytokines in Salmonella infection. Clin Exp Immunol 131, 111-117.

Ogden CL, Kuczmarski RJ, Flegal KM, Mei Z, Guo S, Wei R, Grummer-Strawn LM, Curtin LR, Roche AF \& Johnson CL (2002) Centers for Disease Control and Prevention 2000 growth charts for the United States: improvements to the 1977 National Center for Health Statisitics version. Pediatrics 109, 45-60.

Ramakrishnan U, Latham MC, Abel R \& Frongillo EA Jr (1995) Vitamin A supplementation does not improve physical growth of preschool children: a randomized double blind field trial in South India. J Nutr 125, 202-211.

Sempertegui F, Estrella B, Camaniero V, Betancourt V, Izurieta R, Ortiz W, Fiallo E, Troya S, Rodriguez A \& Griffiths JK (1999) The beneficial effect of weekly low-dose vitamin A supplementation on acute respiratory infections and diarrhea in Ecuadorian children. Pediatrics 104, e1.

Stansfield SK, Pierre-Louis M, Lerebours G \& Augustin A (1993) Vitamin A supplementation and increased prevalence of childhood diarrhea and acute respiratory infections. Lancet 342, 578-582.

VanCott JL, Franco MA, Greenberg HB, Sabbaj S, Tang B, Murray R \& McGhee JR (2000) Protective immunity to rotavirus shedding in the absence of interleukin-6: Th1 cells and immunoglobulin A develop normally. J Virol 74, 5250-5256.

Velazquez FR, Garcia-Lozano H, Rodriguez E, et al. (2004) Diarrhea morbidity and mortality in Mexican children. Pediatr Infect Dis $J$ 23, S149-S155.

Velazquez FR, Matson DO, Calva JJ, Guerrero L, Morrow AL, Carter-Campbell S, Glass RI, Estes MK, Pickering LK \& RuizPalacios GM (1996) Rotavirus infections in infants as protection against subsequent infections. $N$ Engl J Med 335, 1022-1028.

Villalpando S, Montalvo-Velarde I, Zambrano N, Garcia-Guerra A, Ramirez-Silva CI, Shamah-Levy T \& Rivera JA (2003) Vitamins $\mathrm{A}$, and $\mathrm{C}$ and folate status in Mexican children under 12 years and women 12-49 years: a probabilistic national survey. Salud Publ Mexico 45, S508-S519.

Wiedermann U, Hanson LA, Holmgren J \& Dahlgren UI (1993) Impaired mucosal antibody response to cholera toxin in vitamin A-deficient rats immunized with oral cholera vaccine. Infect Immun 61, 3952-3957.

Wilhelmi RE \& A S-F (2003) Viruses causing gastroenteritis. Clin Microbial Infect 9, 247-262. 